\title{
Comprehensive study of distributions of residual stress and Young's modulus in large-diameter sugi (Cryptomeria japonica) log
}

\author{
Miyuki Matsuo-Ueda ${ }^{1,3}$ (D) Tsubasa Tsunezumi ${ }^{1} \cdot$ Zhuoting Jiang $^{1}$ (D) \\ Masato Yoshida ${ }^{1}$ (D) Kana Yamashita ${ }^{2}$ (D) Yosuke Matsuda ${ }^{2}$. \\ Yukari Matsumura $^{2} \cdot$ Yuji Ikami $^{2} \cdot$ Hiroyuki Yamamoto $^{1}$ (D)
}

Received: 5 July 2021 / Accepted: 27 January 2022 / Published online: 24 February 2022

(c) The Author(s) 2022

\begin{abstract}
Aged conifer forests in Japan are expected to produce large-diameter logs, defined as $\log$ s with a top-end diameter of $30 \mathrm{~cm}$ or more. However, the knowledge and techniques for industrial processing of large-diameter logs of Japanese wood species have not been sufficiently developed. This study was aimed at characterizing the longitudinal component of residual stress distribution of large-diameter logs of sugi (Japanese cedar, Cryptomeria japonica), a major tree species cultivated in Japan, as the processing yield of primary lumber from large-diameter logs is affected by the magnitude and distribution pattern of the residual stress. The radial distributions of the released strain of residual stress, tensile Young's modulus, and residual stress were measured using 63 logs. The radial distributions of the released strain and residual stress showed typical patterns reported in previous studies: contraction near the bark and elongation near the pith in the released strain, tensile stress near the bark, and compressive stress near the pith. The radial distributions of Young's modulus showed a typical pattern: low near the pith and high near the bark. The difference between the maximum and minimum released strains in each log varied widely among individuals, which was expected to result in a wide variation in crooking when rip sawing. The longitudinal uniformity and axial symmetry of the radial distribution of the released strain and residual stress were experimentally confirmed, which lays the groundwork for improved understanding of the residual stress in sugi logs.
\end{abstract}

Miyuki Matsuo-Ueda

matsuo.miyuki.4d@kyoto-u.ac.jp

1 Graduate School of Bioagricultural Sciences, Nagoya University, Nagoya, Japan

2 Forest and Forest Products Research Institute, Tsukuba, Japan

3 Research Institute for Sustainable Humanosphere, Kyoto University, Uji, Japan 


\section{Introduction}

In the 1960s, forest plantations were promoted in Japan, and the area of such plantations increased greatly to satisfy the increasing domestic demand for wood. The excess demand for wood subsequently changed into excess supply, causing stagnation in forestry production activities, and wood production decreased until the 2000s (Forestry Agency, Ministry of Agriculture, Forestry and Fisheries Japan 2013). Approximately $40 \%$ of forests in Japan are planted, mostly conifer trees, covering nearly 10.5 million hectares. The growing stock is steadily expanding, mainly in planted forests, and reached approximately 3.3 billion $\mathrm{m}^{3}$ from planted forests by the end of March 2017. Half of the planted forests are more than 50 years old and are entering their harvesting period (Forestry Agency, Ministry of Agriculture, Forestry and Fisheries Japan 2019).

Aged forests are expected to produce large-diameter logs, which are logs with a top-end diameter of $30 \mathrm{~cm}$ or more, as defined by the Japanese Agricultural Standards for Logs (Ministry of Agriculture, Forestry and Fisheries Japan 2007). However, the knowledge and techniques for industrial processing of large-diameter logs of Japanese wood species have not been sufficiently developed because small- or middle-diameter logs have been the main products. The lack of knowledge and techniques has caused a bottleneck in the utilization of large-diameter logs. As wood production has slightly increased in the last two decades (Forestry Agency, Ministry of Agriculture, Forestry and Fisheries Japan 2019), developing a technique based on scientific studies will help the wood industry and be a great opportunity to increase the consumption of forest products in Japan. Thus, the Forestry Agency led the "large-diameter log project" to develop knowledge and techniques concerning the harvesting, grading, sawing, and drying of largediameter logs.

Large-diameter logs enable the production of square lumber without the pith, or at one side of the pith, from a single log, while lumber with a usually centered pith is sawn from a single small- or middle-diameter log. Lumber without the pith is crooked by the redistribution of the residual stress in the tree.

During the growth of a straight tree, growth stress (or surface growth stress) is generated in newly formed xylem. Then, the surface growth stresses accumulated during the secondary growth cause the 3-D distribution of stress in the trunk, which is referred to as residual stress. The longitudinal component of the residual stress (hereinafter, the residual stress) generally shows tensile stress near the bark and compressive stress around the pith. The redistribution of the residual stress by sawing lumber, especially ripping along the pith, causes lumber crooking (Archer 1987; Kübler 1987; Gril et al. 2017).

The magnitude and distribution pattern of the residual stress control the extent of crooking (Okuyama and Sasaki 1979; Ormarsson et al. 2009; Yamamoto et al. 2021). Crooking requires multiple sawings to correct the dimensions, resulting in a decrease in yield. The yield of lumber from large-diameter logs is also affected by the sawing pattern (Matsumura et al. 2012, 2013), namely, the process of releasing the residual stress. To improve the yield, it is important to characterize 
the residual stress of logs in relation to the distortion by various sawing patterns. Several large-scale studies have been conducted to understand the characteristics of residual stress distributions primarily for hardwood or fast-growing species in which crooking due to residual stress was severe: over 200 Eucalyptus trees (Eucalyptus gigantea) (Jacobs 1945), 202 beech trees (Fagus silvatica) (Nikolov et al. 1968) and 86 beech trees (Saurat and Guéneau 1976). Growth stress and its related problems have also been highlighted for softwood species (Johansson and Ormarsson 2009; Ormarsson et al. 2009). However, few systematic studies for softwood species have been conducted, with Nikolov et al. (1967) investigating 33 pine trees (Pinus sylvestris), 30 spruce trees (Picea excelsa) and 81 fir trees (Abies alba).

In this study, the aim was to characterize the residual stress distribution in largediameter sugi (Japanese cedar, Cryptomeria japonica) logs. Sugi is a major softwood species cultivated in Japan and accounts for $58 \%$ of the volume of the domestic wood supply; it is mostly used as sawn lumber. Although the artificial forests of sugi in Japan are in steep mountains, they grow very straight and tall owing to careful maintenance of frequent thinning and pruning. The decrease in yield of largediameter sugi logs due to residual stress is not as severe compared to hardwood or fast-growing species; however, the economic loss due to lumber crooking is considered serious. In this study, a sufficient number of large-diameter sugi logs was used to measure the longitudinal component of the released strain of the residual stress (hereinafter, the released strain) and the tensile Young's modulus. The radial distribution of the residual stress and its variation among individuals were characterized by calculating the residual stress from the released strain and Young's modulus. It was also attempted to clarify whether the residual stress distributions were uniform in the same trunk. The results will promote further studies on growth stress and related problems.

\section{Materials and methods}

\section{Materials}

Sixty-three logs of sugi from Ibaraki Prefecture, Japan, were used. Logs that are as symmetrical as possible were selected for the model experiment. The logs were $4 \mathrm{~m}$ long and had top-end diameters of $33.7-45.9 \mathrm{~cm}$. Table 1 shows the averages, standard deviations, and maximum and minimum values of fundamental log data: number of growth rings of butt end of the logs, weight, length, diameter, density, and dynamic Young's modulus by the tapping method. The trees were felled between 1 and 3 months before the experiment and stored outside at a log market. The logs were brought to the experiment site 2 weeks before the experiment. They were debarked, covered with a tarp to avoid drying, and stored outside until the experiment.

Sample preparation and log processing are shown in Figs. 1 and 2, respectively. Each $4 \mathrm{~m}$ log was cut into end-matched pairs of $2 \mathrm{~m}$ butt-end and $2 \mathrm{~m}$ top-end logs (Figs. 1a and 2a). Two pairs were used to compare the residual stress distributions 


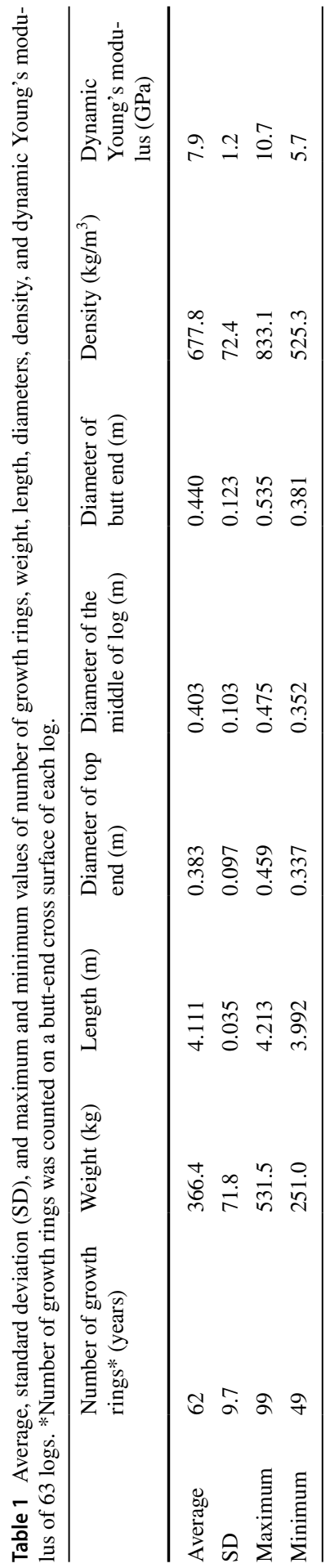



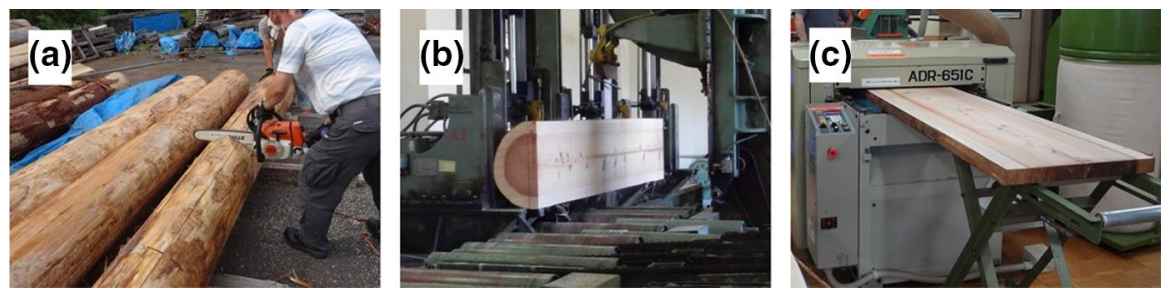

Fig. 1 Log processing: a crosscutting of a $4 \mathrm{~m} \log$ into $2 \mathrm{~m} \operatorname{logs}$, b rough sawing of a board by using a single bandsaw, and $\mathbf{c}$ smoothing and thickness tuning by using a planer

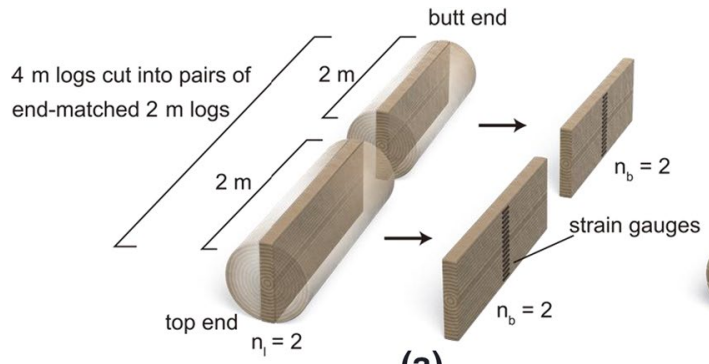

(a)

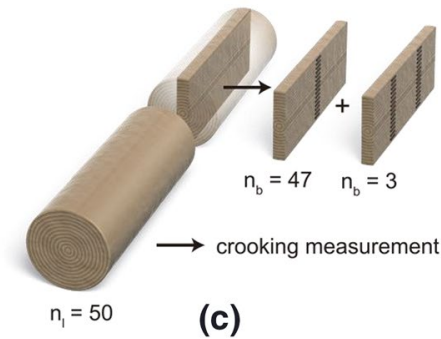

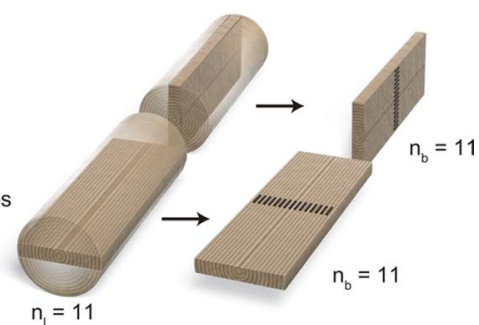

(b) $\mathrm{n}$ : number of $4 \mathrm{~m}$ logs

$\mathrm{n}_{\mathrm{b}}$ : number of boards

Fig. 2 Sample preparation and geometry

among different tree heights in the same longitudinal plane (Fig. 2a), while 11 endmatched pairs were used to compare the residual stress distribution in the longitudinal planes perpendicular to each other (Fig. 2b). For the other 50 end-matched pairs, the butt-end logs were used to measure the residual stress, and the top-end logs were rip sawn to measure crooking (Fig. 2c). Three butt-end logs from these pairs were also used to check the uniformity of the residual stress among different tree heights in the same plane (Fig. 2c).

Five-centimeter unedged boards with pith were sawn by using a bandsaw and planed using a single surface planer into $4 \mathrm{~cm}$ boards, with the pith positioned $1 \mathrm{~cm}$ from the surface (Figs. 1b and c). Immediately after planning, the boards were covered with a plastic sheet to avoid drying, and strain measurement was performed within 2 days. The moisture contents of the boards were measured after the whole experiment and confirmed that the samples remained above the fiber saturation point throughout the experiment. 


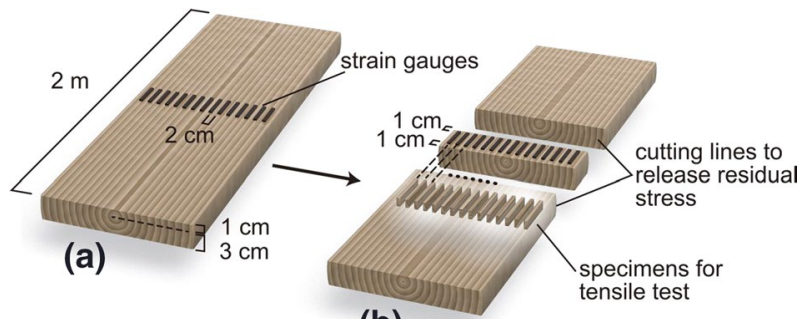

(b)

Fig. 3 Board geometry for measurement of released strain and tensile test
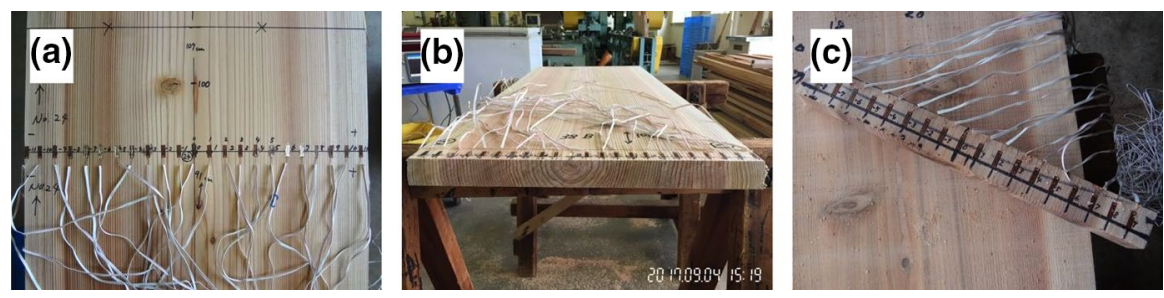

Fig. 4 Measurement of released strain of the residual stress: a strain gauges on a board, $\mathbf{b}$ after crosscutting one side adjacent to strain gauges by using a handsaw to release the residual stress, and $\mathbf{c}$ a strip after releasing the residual stress

\section{Methods}

\section{Measurement of longitudinal residual stress}

The distribution of the released strain across the diameter was measured using strain gauges (KFGS-10-120-C1-11 L3M3R, gauge length $10 \mathrm{~mm}$; Kyowa Electronic Instruments Co., Ltd., Tokyo, Japan). The measuring points were set on the surface near the pith and in the middle of each board to avoid defects such as knots and cracks (Figs. 3a and 4a). The strain gauges were glued with cyanoacrylate glue (CC33A; Kyowa Electronic Instruments Co., Ltd.) along the longitudinal direction of the boards. The distance between the gauges was $2 \mathrm{~cm}$.

The strains were monitored using a data logger (UCAM-550A; Kyowa Electronic Instruments Co., Ltd.). The initial strains were measured using an upright board. Then, the residual stress was released by cutting the boards by using a handsaw at $1 \mathrm{~cm}$ from each end of the strain gauges (Figs. 3b, 4b, and 4c), after which the strain was measured again. The released strain was calculated as the difference between the initial strain and the strain after cutting.

\section{Measurement of Young's modulus}

Specimens for the tensile test were cut from corresponding positions on the same board (Fig. 3b). The specimen dimensions were $100 \mathrm{~mm}$ (longitudinal direction $) \times 10 \mathrm{~mm}$ (tangential direction) $\times 5 \mathrm{~mm}$ (radial direction). The specimens were 
kept wet until testing. After measuring the cross-sectional areas, strain gauges (KFGS-5-120-C1-11, gauge length 5 mm; Kyowa Electronic Instruments Co., Ltd.) were glued in the middle of both tangential surfaces of the specimens. To avoid the slipping of the specimen from the tensile jig, water-resistant sandpaper was glued between each specimen and the jig or a pair of small hardwood blocks was glued to the side of the specimen. The test was performed using a universal testing machine (SH-14NB-50R3; Imada Seisakusho Co., Ltd., Aichi, Japan). The strain and load during the test were monitored using a data logger (UCAM-1A; Kyowa Electronic Instruments Co., Ltd.) and a load cell, respectively, up to a maximum load of $400 \mathrm{~N}$. The Young's modulus was calculated from the linear region of the load-strain curve and cross-sectional areas.

\section{Calculation of residual stress}

The residual stress was calculated from the released strain and Young's modulus as follows:

$$
\sigma_{\eta}=-\varepsilon_{\eta} E_{\eta}
$$

where $\eta$ indicates the distance from the pith along the radial direction, and $\sigma_{\eta}, \varepsilon_{\eta}$, and $E_{\eta}$ are the residual stress, released strain, and Young's modulus, respectively, at the distance $\eta$.

\section{Results and discussion}

\section{Distribution of released strain, young's modulus, and residual stress}

Figure 5 shows the distribution across the diameter of the averages of the released strain, Young's modulus, and residual stress. The average released strain showed contraction on the bark side, an increase toward the pith, and elongation at one-third of the distance from the pith, with the maximum at the pith. This is similar to the typically reported released strain distributions in sugi wood (Sasaki and Okuyama 1981; Okuyama and Yamamoto 1992; Tejada et al. 1997).
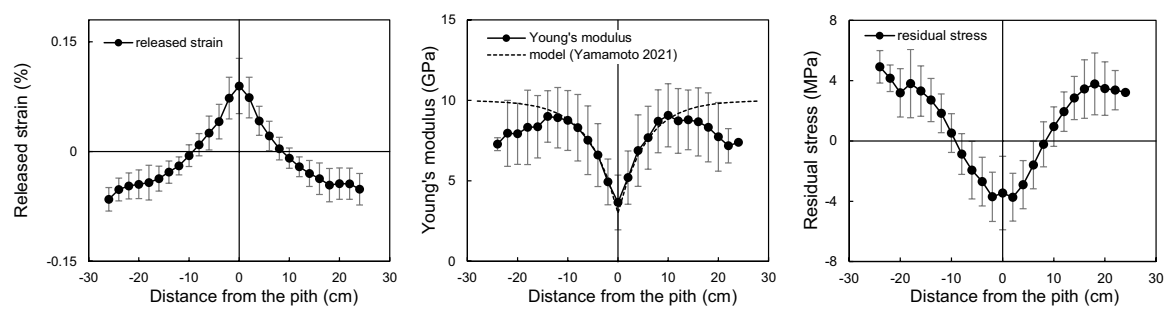

Fig. 5 Radial distribution of the averages of the released strain of the residual stress, Young's modulus, and residual stress. As one log from end-matched pairs was omitted when the Young's modulus was measured on the other log, the numbers of the radial distributions were not the same: released strain, $n=79$; Young's modulus and residual stress, $n=69$ 
The average Young's modulus was rather small near the bark, slightly increased toward the inner xylem, then decreased toward the pith, with the minimum at the pith. Several studies on sugi wood have shown that Young's modulus is low near the pith due to juvenile wood and monotonously increases toward the bark or increases and then becomes constant near the bark (Watanabe et al. 1964; Hirakawa et al. 1997; Iijima et al. 1997; Zhu et al. 2003; Tadooka et al. 2005). The model of Young's modulus distribution (Yamamoto et al. 2021), which was proposed based on previous studies, was also drawn on the same figure. The measured average distribution fitted well to the typical pattern expressed by the model at the inner xylem but was smaller near the bark.

The distribution pattern of the average residual stress was similar to that of the average released strain as the variation in Young's modulus was not too large. The average residual stress was tensile stress on the bark side, which then transitioned into compressive stress, reaching the maximum near the pith. This is similar to the measured and modeled distribution patterns in previous studies (Okuyama and Sasaki 1979; Sasaki and Okuyama 1981, 1983). However, as Young's modulus was lower near the pith, the absolute level of the average residual stress near the pith was rather lower when compared with the average residual strain.

\section{Variation in Young's modulus}

To clarify the reason for deviation of the average values of Young's modulus from the typical pattern near the bark (Fig. 5), the distribution patterns obtained were analyzed in detail. Radial distribution of the Young's modulus in a single board was separated at the pith into two radial distributions from the pith to the bark and averaged for each radius (Fig. 6). Radial distributions of the Young's modulus for each radius showed a typical pattern: low near the pith and high near the bark. However, the Young's modulus of larger-radius $(20,22$, and $24 \mathrm{~cm})$ samples was lower than that of smaller-radius $(14,16$, and $18 \mathrm{~cm})$ samples, resulting in the low average values of whole samples at a larger distance from the pith (Fig. 5). Further studies are required to reveal the differences in Young's modulus among different radii, considering the possible factors affecting Young's modulus such as density, microfibril
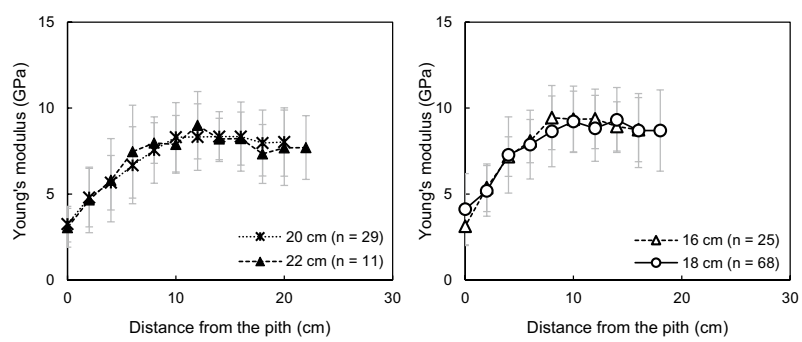

Fig. 6 Radial distribution of the averages of Young's modulus separately averaged for different radii with the number $(n)$ of distribution data for each radius. Left: radius of 20 and $22 \mathrm{~cm}$. Right: radius of 16 and $18 \mathrm{~cm}$. The data of $24 \mathrm{~cm}(n=4)$ and $14 \mathrm{~cm}(n=1)$ are omitted from the graphs as their numbers were small 
angle, and annual ring width (Hirakawa et al. 1997; Yamashita et al. 2000; Ando et al. 2018).

\section{Comparison of the radial distribution of the released strain with other wood species}

To see the relative scale of sugi, the distribution of the average released strain was compared with that of other wood species. The data were derived from previous studies that used the same measuring method, namely the strain gauge method using boards with pith. Figure 7 shows the comparison between the average released strain in this study (Fig. 5) and the released strain of sugi (Tejada et al. 1997), karamatsu (Japanese larch, Larix sp.) (Okuyama et al. 1987), mangium (Acacia mangium) (Wahyudi et al. 1999), falcata (Paraserianthes falcataria) (Wahyudi et al. 2000), teak (Tectona grandis) (Wahyudi et al. 2001), and keyaki (Japanese zelkova, Zelkova
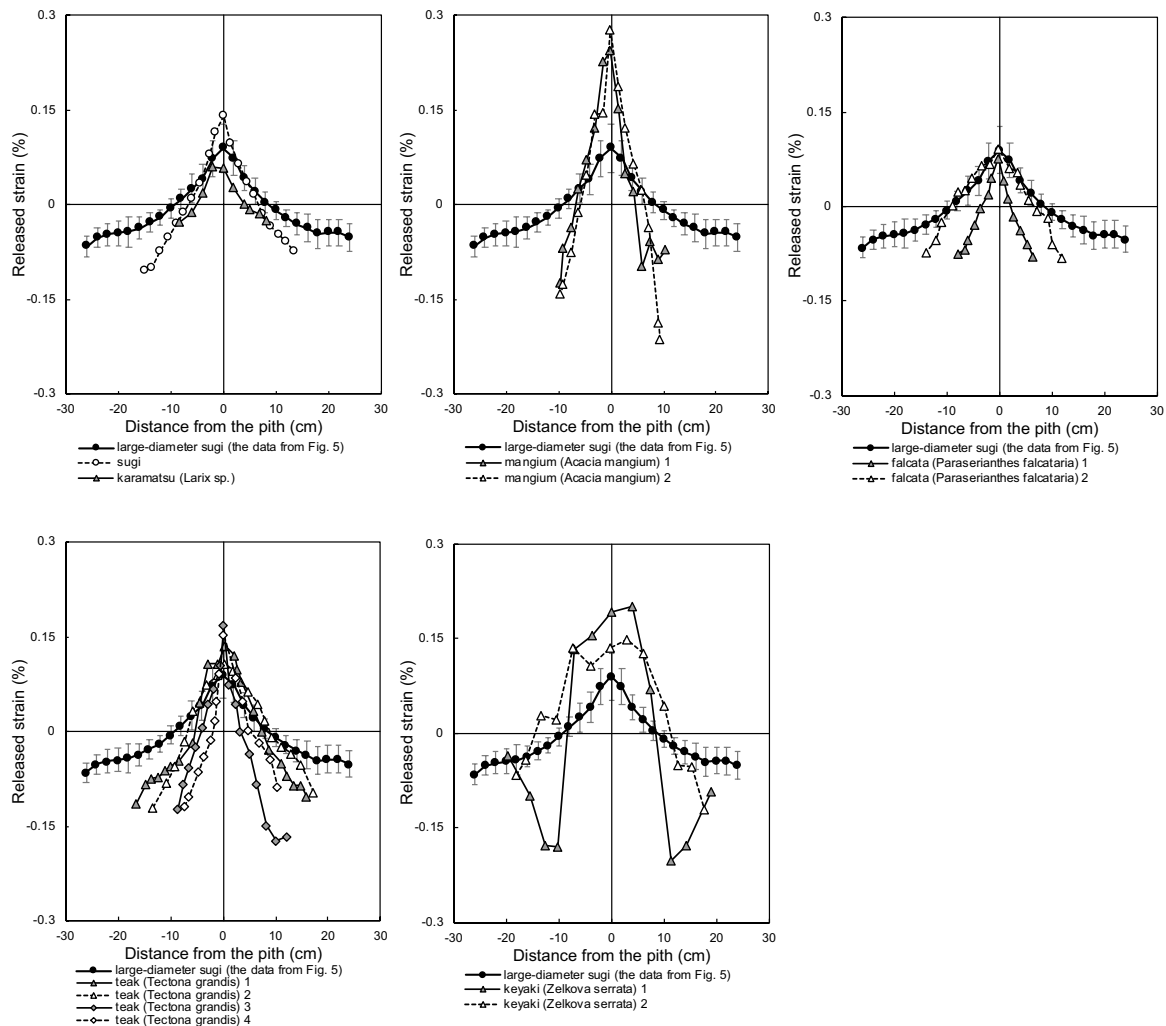

Fig. 7 Comparison of the radial distributions of the average released strain with the data from the previous literature: sugi (Tejada et al. 1997), karamatsu (Japanese larch, Larix sp.) (Okuyama et al. 1987), mangium (Acacia mangium) (Wahyudi et al. 1999), falcata (Paraserianthes falcataria) (Wahyudi et al. 2000), teak (Tectona grandis) (Wahyudi et al. 2001), and keyaki (Japanese zelkova, Zelkova serrata) (Okuyama et al. 1987) 
serrata) (Okuyama et al. 1987). Note that the numbers of samples in these studies were smaller than the present study. Each line expresses a single tree. The comparison shows the distributions of released strain tended to be steeper and their magnitudes were higher in hardwood than in softwood. Thus, the results support that the residual stress and related problems are more severe in hardwood species than in softwood species. This comparison also shows that the distribution of released strain of planted sugi trees was highly uniform.

\section{Variation in the radial distribution of the released strain of residual stress}

Here, the individual characteristics of the radial distribution of the longitudinal released strain is described as the indicator of the longitudinal residual stress (e.g., Archer 1987; Gril et al. 2017). Figure 8 shows the representative patterns observed in this study. Most individuals had the patterns shown in Fig. 8a1 and a2. Figure 8a1 shows a large difference between the maximum and minimum strain or stress, whereas in Fig. 8a2, the difference is rather small. The log of Fig. 8a1 was expected to have a larger crook by rip sawing than that of Fig. 8a2 (Okuyama and Sasaki 1979). Some individuals exhibited the pattern shown in Fig. 8b. They also exhibited a typical pattern, as shown in Fig. 8a1 and a2, but had irregular local strain or stress that would be caused by locally formed compression wood. If the disturbance of this local stress was small, the local stress was not expected to affect the crooking way of large-scale lumber, but it affected the shape of the rip-sawn thin lumber. If the area of compression wood is large, the distortion of compression wood should be considered, but it is rare to exhibit such logs with large compression wood as straight sugi logs at log markets in Japan. A few individuals showed the pattern in Fig. 8c. The released strain and residual stress oscillated throughout the diameter without a clear peak near the pith. Although the precise reason for this oscillation pattern was not detected, it could represent the deterioration of the logs or a particular growing environment. The percentages of each pattern are as follows: Fig. 8a1 and a2, 83.5\%; b, $12.7 \%$; and c, 3.8\%. Each individual graph is viewable in Electronic Supplementary Information.

The differences in the strain between the maximum usually observed at the pith and the minimum usually observed near the bark are summarized in histograms (Fig. 9), which were widespread, indicating large variations among individuals.
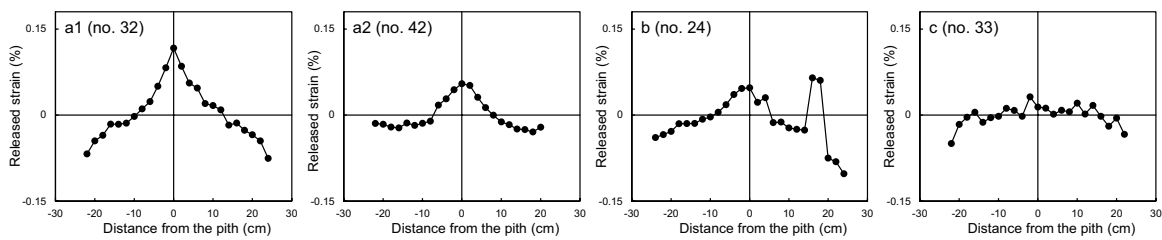

Fig. 8 Observed patterns of the released strain of residual stress. a1 Typical pattern with a large difference between the maximum and minimum strains, $\mathbf{a} 2$ typical pattern with a small difference between the maximum and minimum strains, b typical pattern with irregular local strains, and $\mathbf{c}$ oscillation pattern without a clear peak 

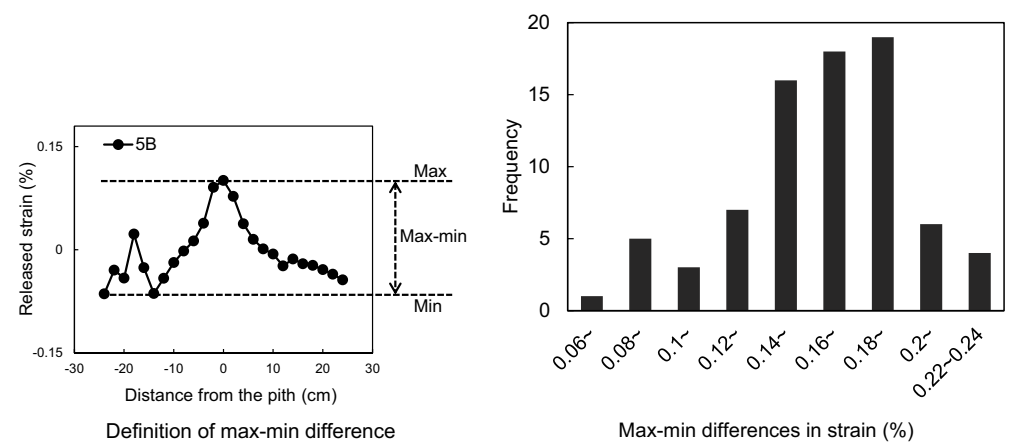

Fig. 9 Definition of differences between the maximum and minimum released strains ("max-min difference") and the histogram of the max-min differences. The maximum released strain is associated with the compressive stress near the pith and the minimum released strain is associated with the tensile stress near the bark

These variations further result in variations in the crook, as the steeper the stress gradient of the radial distribution, the more severe is the crook (Okuyama and Sasaki 1979), indicating the importance of simulation of the crook from the residual stress. In this study, only the characteristics of residual stress are discussed; a comparison between residual stress distribution and the corresponding crooking caused by rip sawing will be reported in a future study.

When simulating lumber crooking due to sawing, simulating the distribution of the residual stress as a function of the relative radial position is practically important (Yamamoto et al. 2021). Yamamoto et al. (2021) proposed three imaginal patterns of residual strain distribution: linear type, Japanese bell type (concave upward parabola), and trumpet pavillon type (concave downward parabola). Okuyama and Sasaki (1979) concluded that the distribution of the residual stress should be modeled by a linear function rather than a logarithmic function for a more accurate simulation of the lumber crook. Based on the shape of each graph of the distribution in this study, the released strain distributions of large-diameter sugi would be regressed to a concave downward parabola function. The residual stress distribution might be described as a linear function or a function that multiplies the released strain, modeled as a concave downward parabola, by Young's modulus, modeled as an exponential function (Yamamoto et al. 2021). A suitable function should be chosen by considering the correspondence between the simulation and the actual crooking, as well as the mechanical explanation of the residual stress generation. Further exploration, including curve-fitting of the observed data, will be important and interesting.

\section{Relationship between the magnitude of the released strain and log characteristics}

Knowing the factor that decides the magnitude of the released strain is important because it enables us to predict lumber deformation by sawing due to the release of residual stress. To examine the possibility of predicting the magnitude of the 
released strain in the early stage of log processing, the relationship between the released strain characteristics defined in Fig. 9 (maximum strain, minimum strain, and the differences between them) and log parameters (number of growth rings, diameter, density of green log, and Young's modulus of log measured by a tapping method) was analyzed (Fig. 10). No significant relationships were noted between the released strain characteristics and log parameters except between the maximum strain and Young's modulus. The maximum strain significantly correlated with Young's modulus $(p<0.05)$, but the correlation was weak $\left(R^{2}=0.14\right)$. Therefore, we need to identify another method for predicting lumber deformation by sawing. The obtained data and samples in this study will enable further investigations, as this is the first large-scale research, to the authors' knowledge, on revealing the variation of the residual stress as well as other physical and mechanical properties of large-diameter sugi logs.

\section{Longitudinal uniformity and axial symmetry of the radial distribution of released strain and residual stress}

Figure 11 shows the radial distribution of the released strain measured at two different longitudinal positions on the same plane. The distributions of no. 37, 39, and 47 in Fig. 11 were measured at two different positions approximately $1 \mathrm{~m}$ apart within a $2 \mathrm{~m}$ board (Fig. 2c), while logs no. 70 and 76 were from two positions approximately $2 \mathrm{~m}$ apart using two end-matched $2 \mathrm{~m}$ boards (Fig. 2a). Figure 12 shows the radial distribution of the released strain measured at two different longitudinal positions on the two planes perpendicular to each other around the pith, and the corresponding radial distribution of Young's modulus measured at the adjacent positions with strain gauges (Fig. 3). Almost all samples had uniform distributions of the released strain between the two positions, except for logs no. 37 and 65 .
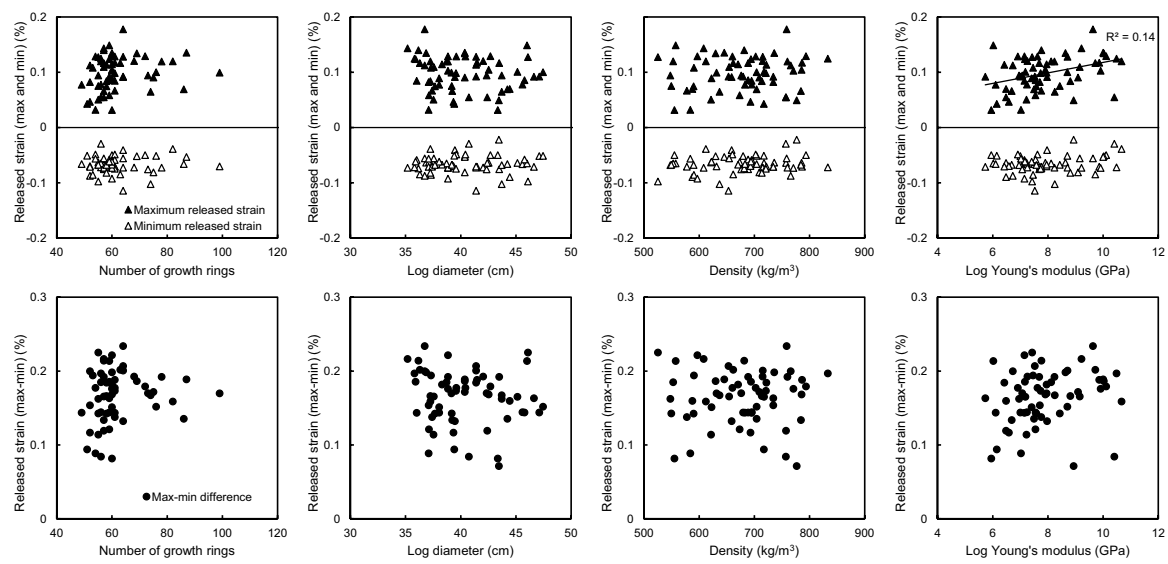

Fig. 10 Relationship between the released strain characteristics (maximum strain associated with the compressive stress, minimum strain associated with the tensile stress, and the differences between them; see Fig. 9 for definitions) and log characteristics (number of growth rings, diameter, green density, Young's modulus of log measured by a tapping method) 


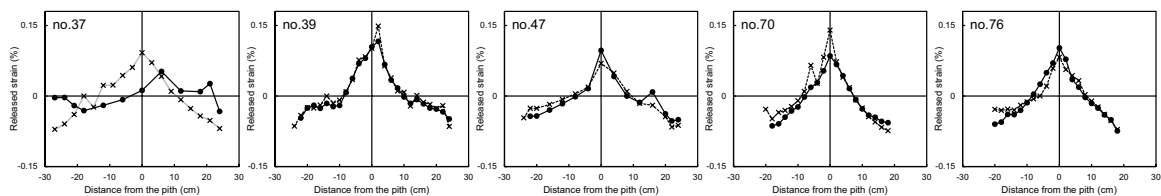

Fig. 11 Radial distribution of the released strain measured at two different longitudinal positions on the same plane. Nos. 37, 39, and 47: measured at two different positions $1 \mathrm{~m}$ apart in the same $2 \mathrm{~m}$ long board; Nos. 70 and 76: measured at two different positions $2 \mathrm{~m}$ apart in two different $2 \mathrm{~m}$ long boards (see Fig. 2). Circle: top log; cross: bottom log

The same results were obtained when the released strain was converted to residual stress because the distribution of Young's modulus were uniform between the two positions as shown in Fig. 12. These results indicated that the distribution of the residual stress had longitudinal uniformity and axial symmetry. There have been almost no studies that demonstrate the uniformity of the distribution within a trunk, although there are many studies on the typical radial distribution of residual stress. The present results provide evidence of the longitudinal uniformity and axial symmetry of residual stress, at least in the case of planted sugi log, which has very straight trunks and grains. This fact is also technically important for further study of lumber deformation due to sawing. The present results enable the comparison of residual stress distribution and corresponding lumber deformation by using the end-matched logs from the same individual tree, given that measuring residual stress distribution is destructive using the current technology.

\section{Conclusion}

In this study, the radial distributions of the released strain of the residual stress, tensile Young's modulus, and residual stress were determined by using 63 largediameter sugi logs. The radial distributions of the released strain, Young's modulus, and residual stress showed typical patterns reported in previous studies. To characterize the residual stress variation of large-diameter sugi logs, the difference between the maximum and minimum released strains in each log was defined and varied widely among individuals; this was expected to result in a wide variation in crooking when rip sawing. The longitudinal uniformity and axial symmetry of the radial distribution of the released strain and residual stress between two end-matched logs cut from a 4-m log were experimentally confirmed, which lays the groundwork for further investigation of the relationship between residual stress distribution and corresponding crooking caused by rip sawing. 


\section{Released strain}
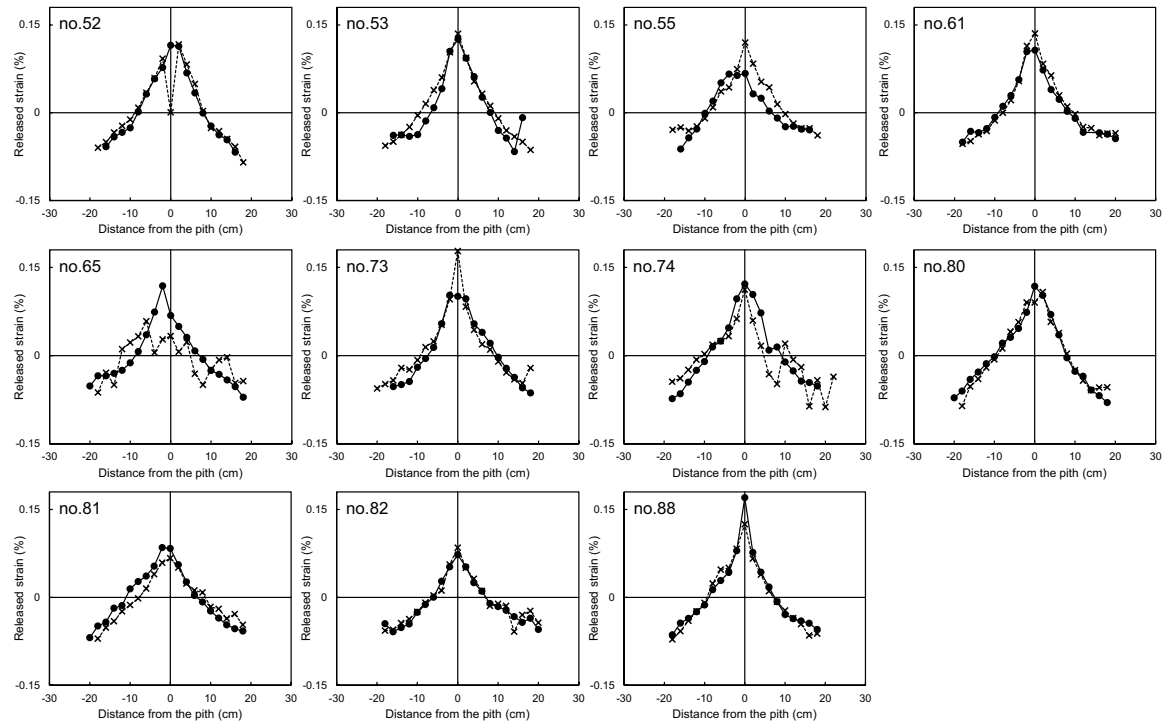

\section{Young's modulus}
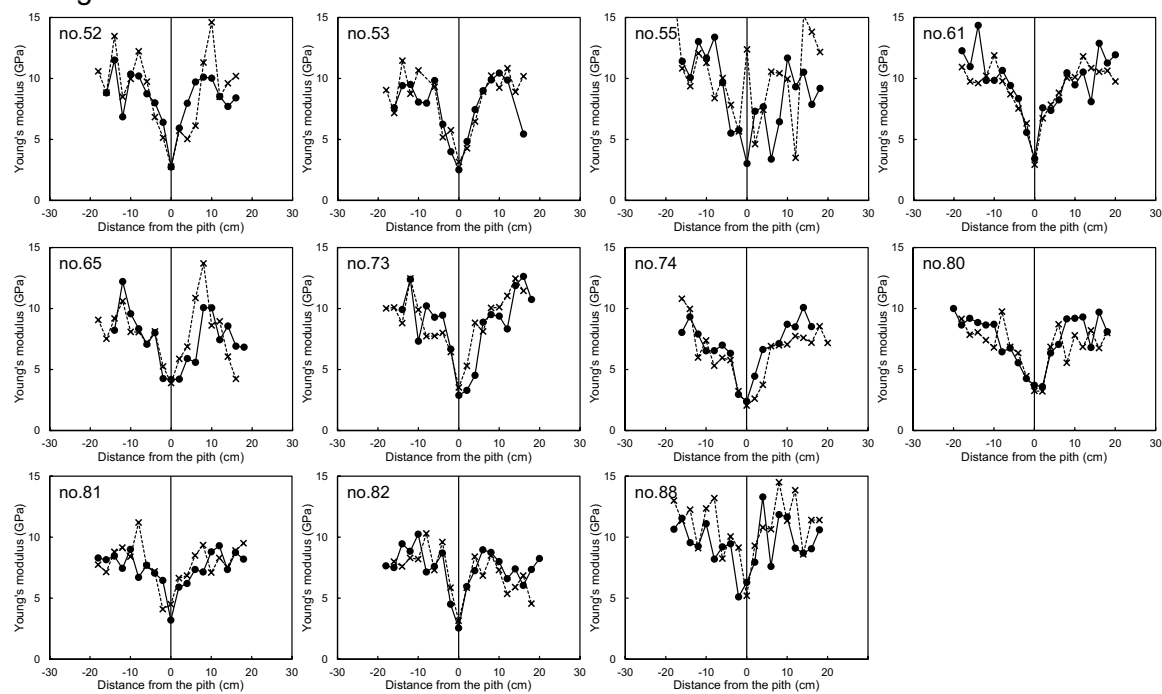

Fig. 12 Radial distributions of the released strain and Young's modulus measured at two different longitudinal positions on two planes perpendicular to each other around the pith. Circle: top log; cross: bottom log. Upper 11 graphs: released strain; lower 11 graphs: Young's modulus

Supplementary Information The online version contains supplementary material available at https://doi. org/10.1007/s00226-022-01360-7. 
Acknowledgements This research was supported by grants from the Project of the Bio-oriented Technology Research Advancement Institution, NARO (the special scheme project on advanced research and development for next-generation technology). The authors are grateful to Dr. M Kojima and Dr. K Toba of FFPRI for helping with our experiments, and Mr. S Suzuki, Mr. J Funyu, Mr. T Kawata, and Mr. S Shimozawa of FFPRI for processing the samples. The authors would like to thank the members of the Laboratory of Wood Physics, Nagoya University, especially Mr. S Muramatsu and Mrs. W Kogawa, for their great help. This work was supported by the Future Development Funding Program of Kyoto University Research Coordination Alliance.

Author contributions MM-U co-supervised this study, conducted the experiment, analyzed the data, and wrote the manuscript. HY leaded the whole project, co-supervised this study, conducted the experiment, and analyzed the data. KY arranged the whole project and conducted the experiment. TT and JZ conducted the experiment and analyzed the data. YM, YM, and YI arranged the sawing process and conducted the experiment. MY co-supervised this study and provided the specific advices to this study.

Funding The Project of the Bio-oriented Technology Research Advancement Institution, NARO (the special scheme project on advanced research and development for next-generation technology). The Future Development Funding Program of Kyoto University Research Coordination Alliance.

\section{Declarations}

Conflict of interest All the authors declared that they have no conflict of interest.

Open Access This article is licensed under a Creative Commons Attribution 4.0 International License, which permits use, sharing, adaptation, distribution and reproduction in any medium or format, as long as you give appropriate credit to the original author(s) and the source, provide a link to the Creative Commons licence, and indicate if changes were made. The images or other third party material in this article are included in the article's Creative Commons licence, unless indicated otherwise in a credit line to the material. If material is not included in the article's Creative Commons licence and your intended use is not permitted by statutory regulation or exceeds the permitted use, you will need to obtain permission directly from the copyright holder. To view a copy of this licence, visit http://creativecommons.org/licen ses/by/4.0/.

\section{References}

Ando K, Mizutani M, Toba K, Yamamoto H (2018) Dependence of Poisson's ratio and Young's modulus on microfibril angle (MFA) in wood. Holzforschung 72:321-327

Archer R (1987) Growth stresses and strains in trees. Springer, Berlin Heidelberg

Forestry Agency, Ministry of Agriculture, Forestry and Fisheries Japan (2013) Annual report on forest and forestry in Japan, fiscal year 2013 (Summary). https://www.maff.go.jp/e/data/publish/attach/pdf/ index-26.pdf. Accessed 6 May 2021, pp 6-10

Forestry Agency, Ministry of Agriculture, Forestry and Fisheries Japan (2019) Annual report on forest and forestry in Japan, fiscal year 2019 (Summary) https://www.maff.go.jp/e/data/publish/attach/pdf/ index-182.pdf. Accessed on 6th May 2021, pp 9-16

Gril J, Jullien D, Bardet S, Yamamoto H (2017) Tree growth stress and related problems. J Wood Sci 63:411-432

Hirakawa Y, Yamashita K, Nakada R, Fujisawa Y (1997) The effects of $S_{2}$ microfibril angle of latewood tracheids and densities on modulus of elasticity variations of sugi tree (Cryptomeria japonica) logs. Mokuzai Gakkaishi (in Japanese with English Abstract) 43:717-724

Iijima Y, Koizumi A, Okazaki Y, Sasaki T, Nakatani H (1997) Strength properties of sugi (Cryptomeria japonica) grown in Akita prefecture III. Some relationships between logs and sawn lumber. Mokuzai Gakkaishi (in Japanese with English Abstract) 43:159-164

Jacobs MR (1945) The growth stresses of woody stems. Commonwealth Aust Forestry Timber Bur Bull 28:1-67 
Johansson M, Ormarsson S (2009) Influence of growth stresses and material properties on distortion of sawn timber-numerical investigation. Ann For Sci 66:604

Kübler H (1987) Growth stresses and related wood properties. Forest Prod Abstract 10:61-119

Matsumura Y, Murata K, Ikami Y, Matsumura J (2012) Influence of sawing patterns on lumber quality and yield in large sugi (Cryptomeria japonica) logs. For Prod J 62:25-31

Matsumura Y, Murata K, Ikami Y, Ikami Y, Ohmori M, Matsumura J (2013) Application of the wood properties of large-diameter sugi (Cryptomeria japonica) logs to sorting logs and sawing patterns. J Wood Sci 59:271-281

Ministry of Agriculture, Forestry and Fisheries Japan (2007) Japanese agricultural standards for logs. https://www.maff.go.jp/j/jas/jas_kikaku/attach/pdf/kikaku_itiran2-147.pdf. Accessed on 20th February 2022, pp 1

Nikolov SV, Videlov HR, Evitimov G, Yosifov B (1967) Biological internal stresses in wood of beech (Fagus silvatica L.). For Univ, Sofia, Sci Works, Series Mech Technol Wood 15:21-31

Nikolov SV, Videlov HR, Evitimov G (1968) Biological internal stresses in the wood of some coniferous species. For Univ, Sofia, Sci Works, Series Mech Technol Wood 16:17-24

Okuyama T, Sasaki Y (1979) Crooking during lumbering due to residual stresses in the tree. Mokuzai Gakkaishi 25:681-687

Okuyama T, Yamamoto H (1992) Residual stress in living tree. In: Fujiwara H, Abe T, Tanaka K (eds) Residual stresses - III Science and Technology. CRC Press, Boca Raton, pp 128-133

Okuyama T, Kanagawa Y, Hattori Y (1987) Reduction of residual stresses in logs by direct heating method. Mokuzai Gakkaishi 33:837-843

Ormarsson S, Dahlblom O, Johansson M (2009) Finite element study of growth stress formation in wood and related distortion of sawn timber. Wood Sci Technol 43:387-403

Sasaki Y, Okuyama T (1981) Determination of the residual stress in a cylinder of inhomogeneous anisotropic material II. Mokuzai Gakkaishi (in Japanese with English Abstract) 27:277-282

Sasaki Y, Okuyama T (1983) Residual stress and dimensional changes on heating green wood. Mokuzai Gakkaishi (in Japanese with English Abstract) 29:302-307

Saurat J, Guéneau P (1976) Growth stresses in beech. Wood Sci Technol 10:111-123

Tadooka N, Koizumi A, Zhu J (2005) The variation in anatomical characteristics and mechanical properties among the stem of Japanese cedar (Cryptomeria japonica). Res Bull Hokkaido Univ For (in Japanese with English Summary) 62:15-30

Tejada A, Okuyama T, Yamamoto H, Yoshida M (1997) Reduction of growth stress in logs by direct heat treatment: assessment of a commercial-scale operation. For Prod J 47:86-93

Wahyudi I, Okuyama T, Hadi YS, Yamamoto H, Yoshida M, Watanabe H (1999) Growth stresses and strains in Acacia mangium. For Prod J 49:77-81

Wahyudi I, Okuyama T, Hadi YS, Yamamoto H, Yoshida M, Watanabe H (2000) Relationship between growth rate and growth stresses in Paraserianthes falcataria grown in Indonesia. J Trop For Prod 6:95-105

Wahyudi I, Okuyama T, Hadi YS, Yamamoto H, Watanabe H, Yoshida M (2001) Relationship between released strain and growth rate in 39 year-old Tectona grandis planted in Indonesia. Holzforschung 55:63-66

Watanabe H, Tsutsumi J, Matsumoto T, Ohta S (1964) Studies on juvenile wood II. On distribution of specific compressive strength and specific modulus of elasticity in stem of Sugi-tree (Cryptomeria japonica D. Don). Mokuzai Gakkaishi (in Japanese with English Abstract) 10:125-130

Yamamoto H, Matsuo-Ueda M, Tsunezumi T, Yoshida M, Yamashita K, Matsumura Y, Matsuda Y, Ikami $\mathrm{Y}$ (2021) Effect of residual stress distribution in a log on lumber warp due to sawing: a numerical simulation based on the beam theory. Wood Sci Technol 55:125-153

Yamashita K, Hirakawa Y, Fujisawa Y, Nakada R (2000) Effects of microfibril angle and density on variation of modulus of elasticity of sugi (Cryptomeria japonica) $\operatorname{logs}$ among eighteen cultivars. Mokuzai Gakkaishi (in Japanese with English Abstract) 46:510-522

Zhu J, Takada K, Iijima Y, Hirakawa Y (2003) Growth and wood quality of sugi (Cryptomeria japonica) planted in Akita prefecture I. Variation of some wood quality indices within tree stems. Mokuzai Gakkaishi (in Japanese with English Abstract) 49:138-145

Publisher's Note Springer Nature remains neutral with regard to jurisdictional claims in published maps and institutional affiliations. 